\title{
Marine microplastic debris: a targeted plan for understanding and quantifying interactions with marine life
}

James R Clark ${ }^{1,2 \dagger}$, Matthew Cole ${ }^{1,2 \dagger}$, Penelope K Lindeque ${ }^{2}$, Elaine Fileman ${ }^{2}$, Jeremy Blackford ${ }^{2}$, Ceri Lewis ${ }^{1}$, Timothy M Lenton ${ }^{1}$, and Tamara S Galloway ${ }^{1 *}$

Microscopic plastic (microplastic) debris is a marine pollutant that threatens aquatic biota and ecosystems. Microplastics have been detected throughout the world's oceans; however, the relative importance of different processes that control the spatial distribution and long-term fate of microplastics in the marine environment remains largely unknown. Results from laboratory and field studies indicate that interactions between microplastic debris and marine organisms may play an important role in redistributing plastic in the oceans. We provide an overview of the various mechanisms through which marine life and microplastics can interact. By considering coupled physical-biological processes, we also identify regions where these interactions are most likely to occur, and outline a new research agenda that aims to determine their prevalence in the marine environment. We hypothesize that biological interactions are key to understanding the movement, impact, and fate of microplastics in the oceans.

Front Ecol Environ 2016; 14(6): 317-324, doi:10.1002/fee.1297

In the past 10 years, more than 2.6 billion metric tons (MT) of plastic have been produced globally (PlasticsEurope 2015). In 2010 alone between 4.8 and 12.7 million MT of plastic are believed to have entered the oceans from terrestrial sources (Jambeck et al. 2015). By comparison, approximately 269,000 MT of plastic regardless of origin - are estimated to float at or near the surface of the world's oceans (Eriksen et al. 2014). Assuming that $50 \%$ of all plastics are positively buoyant in seawater, the total load of buoyant plastic in the oceans represents only about $1-10 \%$ of the amount entering the oceans from land-based activities in 2010. This discrepancy between the amount of plastic entering the

\section{In a nutshell:}

- Microscopic plastics (microplastics) are an abundant and widespread marine pollutant of increasing environmental and economic concern

- Our understanding of the processes determining the longterm fate of plastic in the marine environment is very limited; however, observations suggest that interactions with marine life play an important role in these processes

- Patterns in ocean currents and biological productivity indicate that interactions are most likely to occur in coastal environments, close to sources of plastic contamination

- We propose a targeted research plan to better understand and quantify these interactions and to explore the distribution of microplastic debris throughout the water column

${ }^{1}$ College of Life and Environmental Sciences, University of Exeter, Exeter, UK *(t.s.galloway@exeter.ac.uk); ${ }^{2}$ Plymouth Marine Laboratory, Prospect Place, Plymouth, UK; ${ }^{\dagger}$ these authors contributed equally to this work marine environment, and the amount detected in the oceans remains a mystery, and has led researchers to pose the question: "Where is the missing plastic?" (Cózar et al. 2014; Eriksen et al. 2014; van Sebille et al. 2015).

\section{Our plastic age}

Plastic is a versatile material that provides a vast range of societal benefits, with applications in industry, construction, medicine, and food preservation (Cole et al. 2011). Over the past 70 years, plastic manufacturing has grown exponentially. At the same time, inadequate waste disposal has resulted in large quantities of plastic debris entering the world's oceans (Jambeck et al. 2015). Owing to slow rates of degradation, marine plastic can persist for years, decades, or even centuries (Andrady 2015). Consequently, marine plastic debris is now recognized as a marine pollutant of international environmental, economic, public, and political concern that poses a threat to marine life, industry, and food security (G7 2015).

Marine plastic debris includes items spanning several orders of magnitude in size. While the prevalence of large items (eg discarded fishing gear, plastic bottles and bags) has historically received the most attention (Derraik 2002), in recent years the focus has shifted to include microscopic plastic particles and fibers, collectively termed "microplastics" $(<5-\mathrm{mm}$ diameter; Figure 1) (Thompson et al. 2004; Cole et al. 2011). Microplastics derive from the fragmentation of larger plastics (Andrady 2015) and may also be manufactured directly, for example, as exfoliates in cosmetics (Napper et al. 2015). These plastics enter marine waters via rivers and sewage outflow (Tagg et al. 2015), or diffusely 


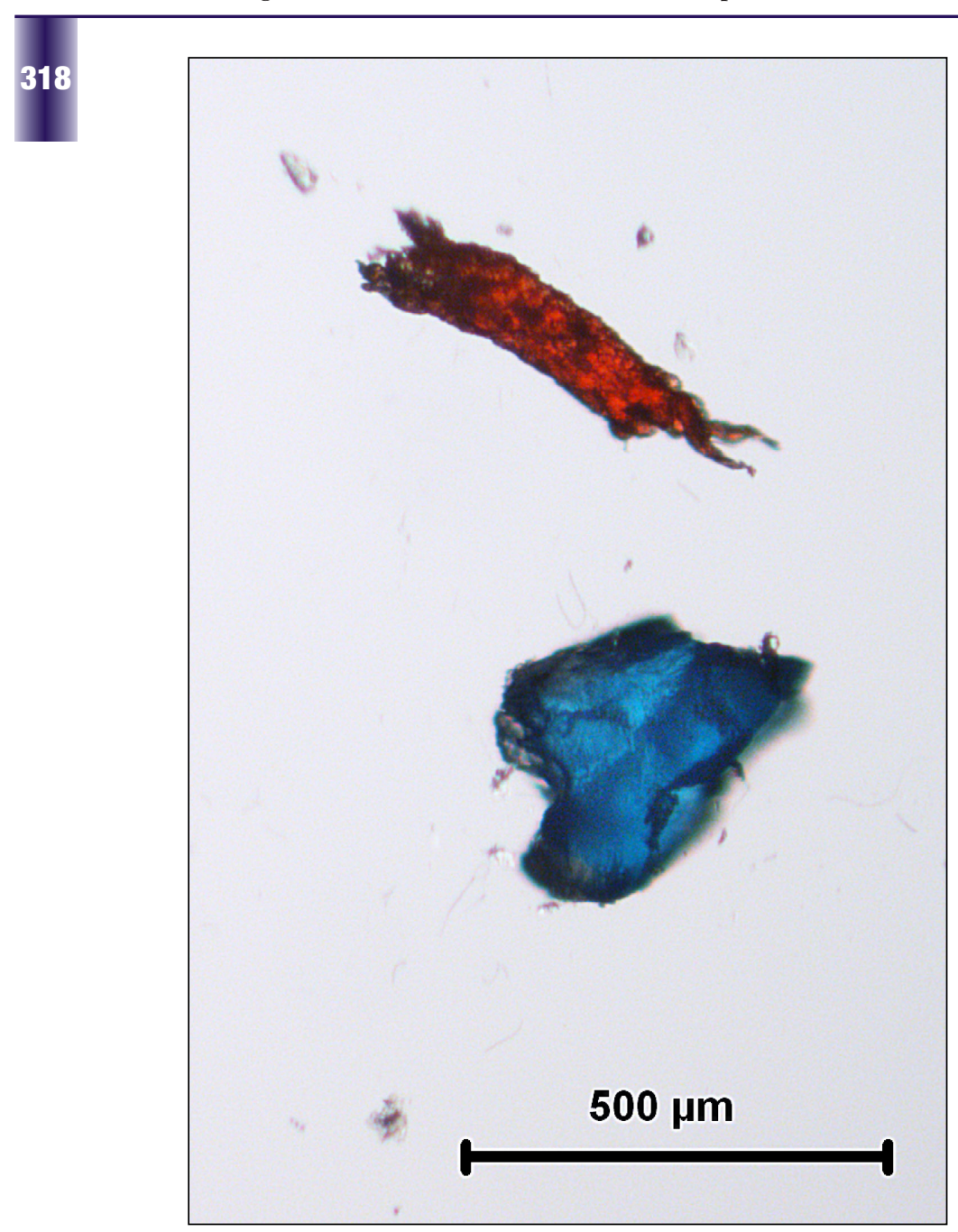

Figure 1. Microscopic plastic (microplastic) debris is a widespread pollutant, impinging on marine ecosystems across the globe. Here, a microscopic red plastic fiber (520-um length) and a blue microplastic fragment (410-um diameter) sampled from sub-surface waters in the Gulf of Maine (US) are shown.

through anthropogenic activities (eg aquaculture, fishing, shipping, or tourism).

In marine waters, microplastic items - depending on their size, shape, and density - can be transported by a variety of different processes. Positively buoyant items will tend to accumulate near the sea surface, where they are transported by winds and surface water currents, whereas negatively buoyant items sink out of the water column to the sediments below (Van Cauwenberghe et al. 2013). As a consequence, microplastics have been detected across the globe, including the open ocean (Law et al. 2010; Cózar et al. 2014; Eriksen et al. 2014), polar icecaps (Obbard et al. 2014), deep-sea sediments (Van Cauwenberghe et al. 2013), and the beaches of remote, mid-oceanic islands (do Sul et al. 2013).

\section{The missing size fraction}

At global scales the movement, spatial distribution, and accumulation of plastics has predominantly been studied from a physical perspective through the use of hydrodynamic models (Lebreton et al. 2012), the tracks of ocean drifters (Maximenko et al. 2012), and sampling campaigns throughout the world's oceans (Cózar et al. 2014; Eriksen et al. 2014). Several estimates now exist for the mass of small buoyant plastics at or near the ocean's surface. The most recent of these uses a superset of the data from two global surveys (Cózar et al. 2014; Eriksen et al. 2014), in combination with three different surface ocean transport models (Lebreton et al. 2012; Maximenko et al. 2012; van Sebille et al. 2015), and arrives at an estimate for the total load of buoyant plastic, measuring $<200 \mathrm{~mm}$ in size, of between 93,300 and 236,000 MT (van Sebille et al. 2015).

Even when accounting for larger macroplastics ( $>200$ mm in size, as defined by Eriksen et al. [2014]), which have been estimated to make up more than $70 \%$ of the total mass of plastic at the ocean's surface, and dense plastic items that rapidly sink out of the water column to the seafloor, it is difficult to reconcile these pool sizes with estimates of plastic inputs to the ocean. Indeed, such calculations suggest plastics are being rapidly removed from the ocean surface by unknown processes.

Models of the expected size distribution of plastics, based on the tendency of larger items to fragment into smaller pieces as a result of photo-degradation and mechanical weathering, suggest that there is a selective removal of microplastics from the ocean (Cózar et al. 2014; Eriksen et al. 2014). Three plausible hypotheses can be invoked to explain the apparent missing size fraction. First, rates of embrittlement followed by fragmentation may be faster for smaller items, leading to the formation of smaller and smaller particles that may be missed by current sampling practices (Hidalgo-Ruz et al. 2012; Andrady 2015). Secondly, biofouling or entanglement with planktonic aggregates may produce a ballasting effect that transfers plastic away from the sea surface (Long et al. 2015). Thirdly, smaller particles may be consumed and cycled by marine organisms, leading to redistribution within the water column and contamination of the food chain (with repercussions for food security).

Below, we draw on our own work and that of others to highlight the importance of interactions between microplastics and marine life. We illustrate how ecological processes - that act in tandem with physical transport processes - can play a role in transporting microplastics away from the sea surface, with implications for both the fate of plastics in the marine environment, and the contamination of marine food chains and commercial seafood.

\section{Plastic distributions in the global ocean - a spatial mismatch}

Large-scale oceanic models predict that buoyant particles that escape over the continental shelf edge to the 
open ocean will accumulate in the subtropical gyres (Maximenko et al. 2012) - a hypothesis supported by sampling efforts in these regions (Law et al. 2010). In Figure 2a, we present a model-based estimate for the spatial distribution of small surface plastics in the North Atlantic and surrounding waters from van Sebille et al. (2015). The model was calibrated against the most comprehensive global dataset for surface plastics assembled to date. To compare the spatial distribution of plastic debris with regions of high biological activity, we show a climatology of annual mean, satellite-derived estimates of sea surface chlorophyll (Figure 2b), which is taken as a proxy for oceanic primary production. Overlain in Figure 2 are Longhurst's Biogeographical Provinces (Longhurst 2006) for the North Atlantic, which divide the region into a small number of physical oceanographic regimes that host distinctive pelagic and benthic communities.

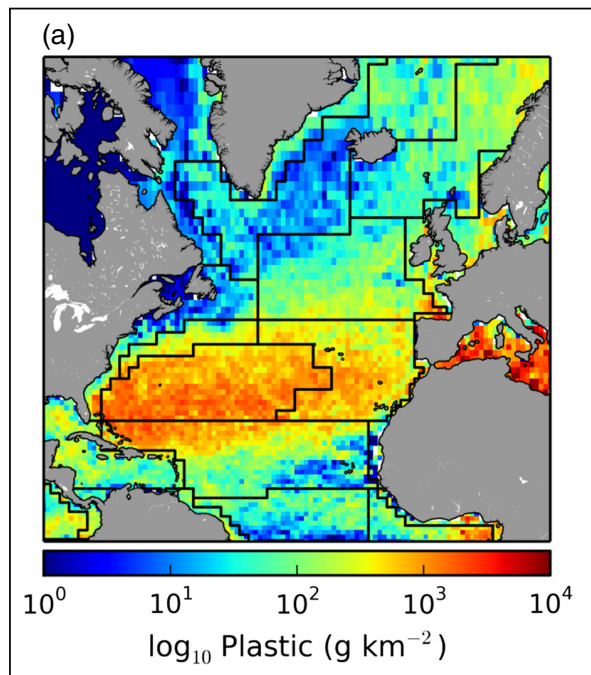

(b)

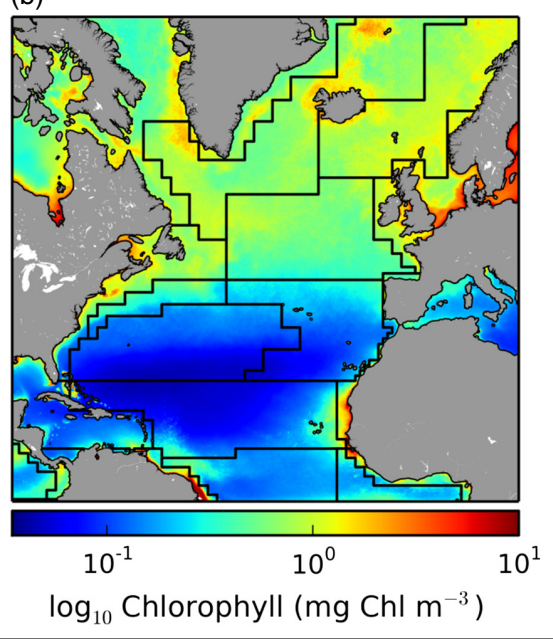

Figure 2. (a) Surface concentration of plastic debris $<200 \mathrm{~mm}$ in size calculated by the model of van Sebille et al. (2012), and calibrated against available data (van Sebille et al. 2015). Data downloaded from https://dx.doi.org/10.6084/m9. figshare.1613256. (b) A climatology of annual mean (1997-2010), satellite-derived estimates of sea surface chlorophyll for the North Atlantic Ocean at $1 / 12^{\circ}$ resolution (SeaWIFS data downloaded from the NASA ocean-color website: http://oceancolor. gsfc.nasa.gov/cms). Thick black lines within the ocean basin show Longhurst Biogeographical Provinces (Longhurst 2006) for the North Atlantic (Version 4, available online: http://marineregions.org). Image created using the matplotlib plotting library, version 1.2 .
Source regions for plastic are largely centered around areas of anthropogenic activity and more densely populated regions. These predominantly discharge within Longhurst's Coastal Biomes, including shelf-sea environments, which tend to be productive, dynamic regions that support a broad range of pelagic and benthic organisms. Despite constituting approximately $8 \%$ of the area of the global ocean, shallow seas overlying the continental shelf are responsible for $15-21 \%$ of global oceanic primary production (Jahnke 2010), and given their proximity to landbased sources of plastic (ie rivers, human activity [including fishing]) the potential for co-occurrence and interactions with marine life is predicted to be high.

Away from the coasts, in the open North Atlantic Ocean, plastics are observed to collect in the North Atlantic Subtropical Gyral Provinces (Figure 2a). The subtropical gyres are regions of anti-cyclonic circulation, which drive surface convergence and downwelling. In turn, downwelling depresses the thermocline (an underwater boundary characterized by a rapid change in temperature with depth) and limits the amount of nutrients supplied to surface waters. Primary production therefore tends to be low in these regions relative to regions of upwelling, such as the subpolar gyres, equatorial regions, and coastal upwelling zones (Williams and Follows 2003). When combined, these observations suggest that in the open ocean there is a spatial mismatch between regions of high production, which are rich in marine life, and regions where plastic tends to accumulate
(Figures 2 and 3). That is not to say biological interactions will not occur in the subtropical gyres. Indeed, the hard surface of plastics suspended in a relatively stable environment may be readily colonized by marine microbes (Amaral-Zettler et al. 2015) and biota reliant on flotsam for transport or oviposition (Goldstein et al. 2012). However, given the low levels of biological activity in the subtropical gyres (Figure 2b; Figure 3), the probability of interactions occurring is predicted to be low.

Like much of the world's oceans, Longhurst's Coastal Biomes are undersampled with respect to microplastics (van Sebille et al. 2015), and the frequency of interactions between microplastics and marine life in these regions remains largely unknown. Because collecting, isolating, and identifying microscopic particulates from vast volumes of water is very complex, most of the existing sampling effort has focused on surface waters using relatively coarse nets (typically 333- $\mu \mathrm{m}$ meshes); this allows for long, uninterrupted sampling transects, which minimize the collection of biological material that can greatly reduce sampling efficiency and mask the presence of plastics (Hidalgo-Ruz et al. 2012; Cole et al. 2014). Data pertaining to larger, buoyant microplastics have proven essential in modeling the risks posed to surface foraging seabirds (Wilcox et al. 2015). Currently, however, there is a lack of data on microplastics within the prey size range of suspension feeding organisms, and on plastics present within the water column where most pelagic animals feed. 


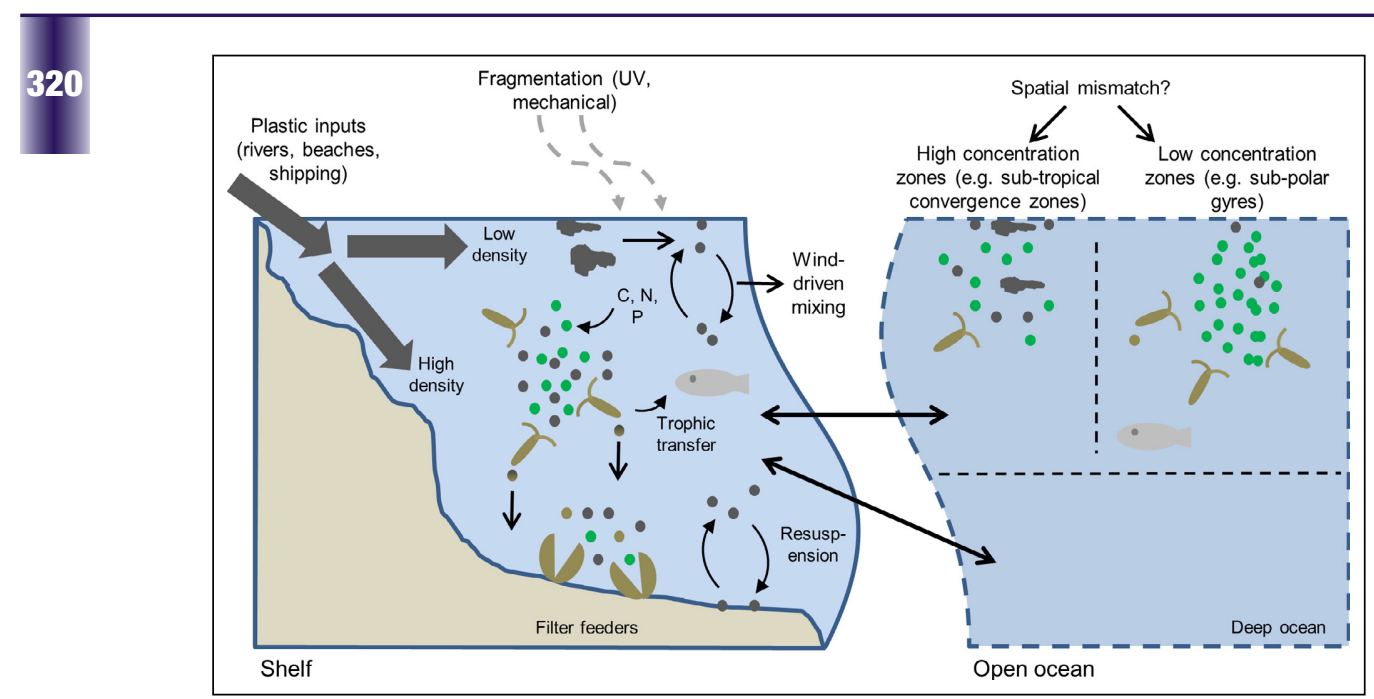

Figure 3. Schematic showing hypothesized regions and modes of interaction between microplastics (dark gray), algal prey items (green), and marine organisms other than algal prey items (brown and light gray). Open ocean (right panel): known areas of high plastic accumulation (eg subtropical convergence zones) have low primary productivity and therefore biological interactions are expected to be less frequent. Shelf seas (left panel): areas with generally high levels of biological productivity that are often close to sources of plastic input, where we predict biological interactions will be more frequent. $\mathrm{UV}$, ultraviolet radiation.

\section{Consumption of plastics by marine life}

The widespread consumption of plastics by marine organisms has been confirmed by biomonitoring studies in which the gut contents of wild marine animals - including foraging seabirds (Wilcox et al. 2015), pelagic and demersal fish (Boerger et al. 2010; Lusher et al. 2012), estuarine crustaceans (Murray and Cowie 2011), and intertidal shellfish (Van Cauwenberghe and Janssen 2014) - have been inspected. These studies revealed that ingestion of microplastic particles and fibers is commonplace. For instance, $34 \%$ of gooseneck barnacles living on flotsam in the North Pacific Subtropical Gyre (Goldstein and Goodwin 2013), 52\% of blue whiting and red gurnard in the English Channel (UK) (Lusher et al. 2012), and 83\% of Norwegian lobsters in the Clyde estuary (UK) (Murray and Cowie 2011) were found to have ingested microplastics. Furthermore, biological transfer of plastic has been evidenced throughout the food chain (eg from fish to Norwegian lobsters [Murray and Cowie 2011], and from copepods to macrozooplankton [Setälä et al. 2014]). Either through direct ingestion, or via trophic transfer, microplastics are also ending up in commercial seafood, including European mussels and oysters (Van Cauwenberghe and Janssen 2014) and fish and shellfish sourced at markets in the US and Indonesia (Rochman et al. 2015).

Given the total levels of biomass production in marine zooplankton and fish, marine organisms clearly have the potential to consume, cycle, and sequester the apparent missing microplastic identified in recent open-ocean surveys. For example, a modelderived estimate of total fish production of 237 million MT per year (dry weights assumed to be $30 \%$ of reported wet weights; Jennings et al. [2008]) is one to two orders of magnitude higher than recent estimates of land-based marine plastic litter production (Jambeck et al. 2015).

Ingested microplastics can result in lethal or sub-lethal health impacts in a variety of marine organisms (Goldstein and Goodwin 2013; Wright et al. 2013; Nelms et al. 2015; Wilcox et al. 2015). In marine copepods, exposure to microplastics can significantly reduce their consumption of algal prey, with repercussions for egg size, hatching success, and survival (Cole et al. 2013, 2015). Consumption of marine plastic debris may also introduce toxic compounds to biota: chemicals (eg emollients, dyes, flame retardants, and antimicrobials) added to plastics during their production, or hydrophobic persistent organic pollutants (eg DDT [dichlorodiphenyltrichloroethane], PCBs [polychlorinated biphenyls]) that adsorb and concentrate to the surface of plastics in the water column, can result in endocrine disruption or cellular toxicity (Galloway 2015; Rochman 2015). In particular, ingestion can affect the consumed plastic by changing its properties (eg reducing its size through mechanical grinding in the intestinal tract, as observed in common shore crabs; Watts et al. 2015) or by transporting the plastic from the location where it was originally ingested. It is hypothesized that plastic - when internalized within motile organisms or their fecal matter - can be transported away from the sea surface (Cole et al. 2016), similar to how carbon is exported from surface waters through the action of the biological carbon pump (Turner 2015).

We propose that ingestion by marine organisms not only allows plastics to be transported to sub-surface waters and ultimately to the seafloor, but also provides a pathway through which plastics can enter the marine food web and be returned to humans through the consumption of seafood.

\section{Marine biota and the sequestration of microplastics to the seafloor?}

An interesting case study is provided by the ingestion of polystyrene microplastics by marine copepods. Copepods are prolific within aquatic ecosystems throughout the globe, and play pivotal roles in marine food webs and nutrient cycling. We have shown that 
suspension feeding copepods can readily consume microplastics (Figure 4a), a process that affects both the organism and the plastic (Cole et al. 2013). Under normal feeding conditions, gut transit times for microplastics are rapid. Our observations show microplastics are bound up with undigested prey items in the hindgut (Figure 4b) and subsequently egested within compact fecal pellets (Figure 4c). Furthermore, plastic consumed by copepods, or present within their fecal pellets, can be trophically transferred to coprophagous animals (Cole et al. 2016).

Because they feed near the surface, copepods will be more susceptible to ingesting polypropylene, polyethylene, or polystyrene, which have densities below that of seawater $\left(\sim 1.02 \mathrm{~g} \mathrm{~cm}^{-3}\right.$; Figure $\left.4 \mathrm{~d}\right)$. Incorporation into fecal pellets, which have densities above that of seawater (Turner 2015), provides a mechanism by which plastics can be transported from surface waters to the sediments below (Cole et al. 2016). However, laboratory experiments have demonstrated that at sufficient concentrations, lowdensity plastics (eg polystyrene) can reduce the density and sinking velocity of copepod-egested fecal pellets (Figure 4c; Cole et al. 2016). These studies show that interactions between plastics and marine life can have two-way feedbacks, including impacts on the distribution of plastics in the marine environment, and on the organisms with which they interact.

When we consider the role that copepods - with their diel vertical migrations and rapidly sinking fecal pellets play in the biological carbon pump and the sequestration of organic material to the seafloor (Turner 2015), it is logical to consider that this transport pathway may also represent an important sink for microplastics. Likewise, microplastics may be vertically transported via the fecal matter of salps, fish, and other pelagic biota; sinking carcasses; and marine aggregates, typically made up of living or dead cells, held together by a polysaccharide mucus (Long et al. 2015).

Plastic contamination of sediments is widespread, although the impacts are unclear (Van Cauwenberghe et al. 2013). While bioturbating benthic organisms may have a role in mixing microplastics deeper into the sediment locking them away from the water column, microplastics at environmentally relevant $5 \%$ (a)

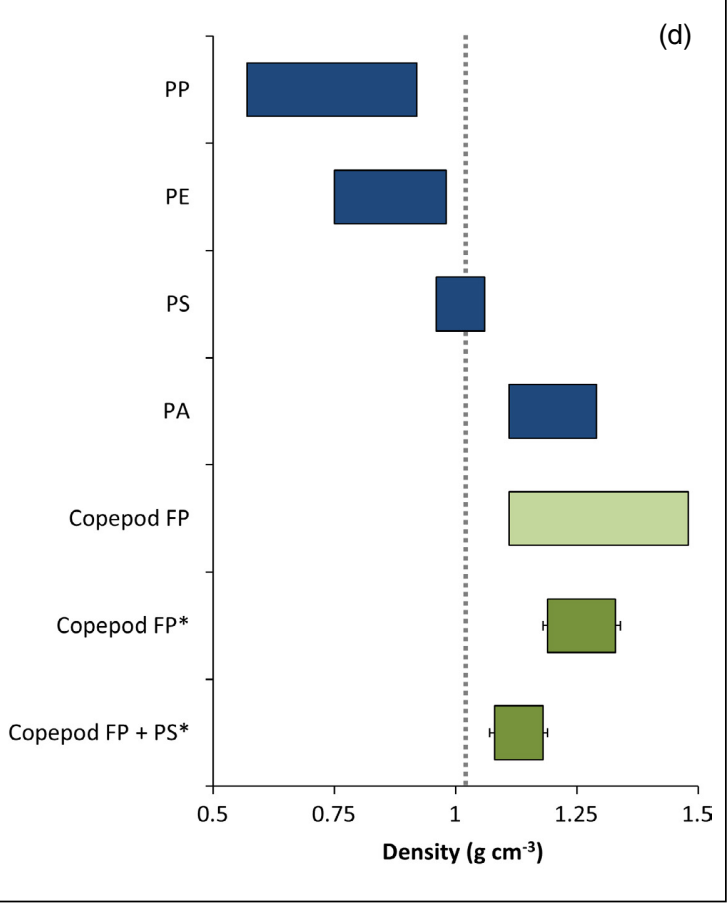

Figure 4. Laboratory experiments illustrate how marine copepods and 20-um polystyrene pellets (FP; light green bar) per literature-derived values; *experimental data (from Cole et al. [2016]; dark green bars) showing the density of copepod (C helgolandicus) fecal pellets with and without polystyrene microplastics; dashed vertical line denotes density of seawater $\left(\sim 1.02 \mathrm{~g} \mathrm{~cm}^{-3}\right)$. Error bars represent standard error of the mean.

weight/weight concentrations can limit the functionality of sediment-dwelling biota (Wright et al. 2013). In shallow shelf-sea environments, plastics sequestered to the sediments may become resuspended due to the action of winds, tides, or waves, and subsequently redistributed within the water column (Lattin et al. 2004). In deeper waters, sediments may become a permanent sink for plastics that either sink out of the water column directly, or are transported over and down the continental slope.

\section{Key questions}

We hypothesize that biological interactions are responsible for the apparent missing size fraction of plastic in the oceans (Figure 3). To assess the prevalence of biological interactions with microplastics in situ and the role that biota play in cycling plastics within the marine environment, we argue that research programs and sampling strategies will be required to consider a broad range of physical and biological processes. We advocate that such a research effort be undertaken and structured around the following hypotheses: 
- $\mathrm{H}_{1}$ : Biological interactions with plastics predominantly occur in regions of high productivity, close to sources of microplastic pollutants (eg rivers, sewage outflows, and coastal cities);

- $\mathrm{H}_{2}$ : Microplastics accumulate within the marine food web, including commercially exploited species of fish and shellfish destined for human consumption; and

- $\mathrm{H}_{3}$ : Marine microplastics are actively consumed and cycled by a variety of marine organisms, including pelagic mesozooplankton and mesopelagic fish. These organisms facilitate the sequestration of plastic to deeper waters and marine sediments.

\section{- Solving the puzzle}

A major challenge for improving the management and protection of the oceans is clearly to develop multiscale, targeted monitoring programs to quantify the frequency and effects of interactions between microplastics and various forms of marine life. The probability of interactions occurring will be highest when high concentrations of plastic coincide in both space and time with high concentrations of marine life (Figure 3). Recent comparisons between the modeled spatial distribution of plastic floating at sea and the geographic range of 186 avian species have improved estimates of the risk of plastic ingestion by foraging seabirds (Wilcox et al. 2015). Surprisingly, the area with the greatest expected impact on biodiversity was identified at the Southern Ocean boundary in the Tasman Sea, which is not one of the main open-ocean accumulation zones identified in modeling studies (eg van Sebille et al. 2015). Furthermore, oceanic fronts (boundaries between distinct water masses) have been highlighted as a region of concern for sea turtles, in which ingested plastic can cause lacerations, intestinal injury, dietary dilution, malnutrition, and poor health outcomes (Nelms et al. 2015).

Conducting similar studies for ocean-dwelling organisms (eg mesopelagic fish, zooplankton) interacting with microplastics will be challenging, and will require a combination of modeling supported by laboratory and observational studies. In these investigations, it will be important to consider: (1) the physical transport of plastic away from known source regions, (2) plastic fragmentation rates and buoyancy changes, (3) the biogeographic range of various species known to ingest or otherwise interact with marine plastic, (4) species feeding patterns, and (5) the impact on both the organism and the plastic.

For different species of wildlife, interaction frequencies and the fate of the microplastic will depend on several key organismal traits. In the case of zooplankton, these frequencies will be determined by the relative size of the organism as compared to that of plastic particles and natural prey items, by its feeding mode, and by prey ingestion rates (Kiørboe 2011). Marine ecological and food web models are beginning to make use of such traits in their construction (eg Litchman et al. 2013), and these may represent a promising means of synthesizing the large amounts of data necessary to establish reliable budget estimates for microplastics. Such models must be combined with physical transport models that are able to simulate realistic spatial and temporal patterns in the abundance of plastic and zooplankton. However, before the output from these models can be relied upon for inference they must first be built, parameterized, and tested using available laboratory and field data.

The identification of Longhurst's Subtropical Gyral Provinces (oceanic gyres) as accumulation zones for surface plastic highlights these regions as areas of potential risk for marine life; notably, $33 \%$ of planktivorous fish sampled within the North Pacific Subtropical Gyral Province were found to have microplastics in their stomachs (Boerger et al. 2010). However, because Longhurst's Coastal Biomes are associated with higher levels of biological production (Figure 2b; Figure 3) and coincide with major source regions of plastic, we hypothesize that interactions here will be more frequent. At present this hypothesis remains untested, and further work is required to identify interaction hotspots for different organisms (Cole et al. 2014).

Smaller microplastics are currently unaccounted for in most monitoring programs and there is a dearth of data for regions of high biological productivity. Increased attention should be given to sampling microplastics and nanoplastics - that is, smaller size fractions $(<333 \mu \mathrm{m}$ in diameter) of plastics that are edible to copepods, mesopelagic fish, and filter-feeding bivalves (Cole et al. 2013; Van Cauwenberghe and Janssen 2014; Koelmans et al. 2015). Kang et al. (2015) found the highest-ever concentration of plastic (15,600 items per cubic meter) in Geoje Bay (South Korea) by using hand nets and on-board pumps to sample microplastics $>50 \mu \mathrm{m}$. Such sampling could be conducted at a variety of depths to assess the vertical distribution of plastics in the water column. Furthermore, by sampling biota and sinking organic matter (ie zooplankton fecal pellets, marine aggregates), it may be possible to determine the propensity for microplastic sequestration and trophic transfer in situ (Cole et al. 2016).

As the human population expands and rates of plastic production grow further, plastic and microplastic litter are expected to pose an increasing risk to marine ecosystems. The global nature of this risk is illustrated by the specific inclusion of marine debris in the G7 summit Strategic Development Goals (SDG target 14.1), which aim to reduce marine pollution of all kinds. In addition, the United Nations Environment Programme has recognized this emerging issue and adopted a resolution to address marine debris and microplastics by encouraging improvements to legislation, waste management, and 
social education (UNEP 2016). To respond to these calls, we need to develop better tools to identify impacted or vulnerable areas or species and to track remedial efforts. We hypothesize that interactions with marine life are key to understanding the ultimate fate of microplastics in the marine environment, and that these interactions will be more frequent in regions of high biological productivity and shelf seas that are adjacent to densely populated coastal towns and cities. Developing an understanding of these interactions is an urgent research goal for improving the management and protection of our oceans from the emerging hazards posed by marine litter.

\section{Acknowledgements}

We thank E van Sebille for providing access to model data on the spatial distribution of small plastics. SeaViewing Wide Field-of-View Sensor (SeaWIFS) data used in this publication were produced by the SeaWIFS project at the Goddard Space Flight Center. The data were obtained from the Goddard Earth Sciences Distributed Active Archive Center under the auspices of the National Aeronautics and Space Administration (NASA). Use of the data is in accord with the SeaWIFS Research Data Use Terms and Agreements. Funding was provided by the Natural Environment Research Council (grant NE/L007010).

\section{References}

Amaral-Zettler LA, Zettler ER, Slikas B, et al. 2015. The biogeography of the Plastisphere: implications for policy. Front Ecol Environ 13: 541-46.

Andrady AL. 2015. Persistence of plastic litter in the oceans. In: Bergmann M, Gutow L, and Klages M (Eds). Marine anthropogenic litter. Cham, Switzerland: Springer International Publishing AG; doi:10.1007/978-3-319-16510-3_3.

Boerger CM, Lattin GL, Moore SL, and Moore CJ. 2010. Plastic ingestion by planktivorous fishes in the North Pacific Central Gyre. Mar Pollut Bull 60: 2275-78.

Cole M, Lindeque P, Fileman E, et al. 2015. The impact of polystyrene microplastics on feeding, function and fecundity in the marine copepod Calanus helgolandicus. Environ Sci Technol 49: 1130-37.

Cole M, Lindeque P, Fileman E, et al. 2013. Microplastic ingestion by zooplankton. Environ Sci Technol 12: 6646-55.

Cole M, Lindeque P, Halsband C, and Galloway TS. 2011. Microplastics as contaminants in the marine environment: a review. Mar Pollut Bull 62: 2588-97.

Cole M, Lindeque PK, Fileman E, et al. 2016. Microplastics alter the properties and sinking rates of zooplankton faecal pellets. Environ Sci Technol 50: 3239-46.

Cole M, Webb H, Lindeque PK, et al. 2014. Isolation of microplastics in biota-rich seawater samples and marine organisms. Sci Rep 4: 4528.

Cózar A, Echevarría F, González-Gordillo JI, et al. 2014. Plastic debris in the open ocean. P Natl Acad Sci USA 111: 10239-44.

Derraik JGB. 2002. The pollution of the marine environment by plastic debris: a review. Mar Pollut Bull 44: 842-52.

do Sul JAI, Costa MF, Barletta M, and Cysneiros FJA. 2013. Pelagic microplastics around an archipelago of the Equatorial Atlantic. Mar Pollut Bull 75: 305-09.
Eriksen M, Lebreton LC, Carson HS, et al. 2014. Plastic pollution in the world's oceans: more than 5 trillion plastic pieces weighing over 250,000 tons afloat at sea. PLoS ONE 9: e111913.

G7. 2015. Future of the ocean: impact of human activities on marine systems. G7 Science Academies; https://royalsociety. org/ /media/news/2015/G7-2015-future-of-the-oceans.pdf. Viewed 10 May 2016.

Galloway TS. 2015. Micro- and nano-plastics and human health. In: Bergmann M, Gutow L, and Klages M (Eds). Marine anthropogenic litter. Cham, Switzerland: Springer International Publishing AG; doi:10.1007/978-3-319-16510-3_13.

Goldstein MC and Goodwin DS. 2013. Gooseneck barnacles (Lepas spp) ingest microplastic debris in the North Pacific Subtropical Gyre. PeerJ 1: e184.

Goldstein MC, Rosenberg M, and Cheng L. 2012. Increased oceanic microplastic debris enhances oviposition in an endemic pelagic insect. Biol Lett 8: 817-20.

Hidalgo-Ruz V, Gutow L, Thompson RC, and Thiel M. 2012. Microplastics in the marine environment: a review of the methods used for identification and quantification. Environ Sci Technol 46: 3060-75.

Jahnke RA. 2010. Global synthesis. In: Liu K-K, Atkinson L, Quinones R, and Talaue-McManus L (Eds). Carbon and nutrient fluxes in continental margins: a global synthesis. Berlin, Germany: Springer-Verlag.

Jambeck JR, Geyer R, Wilcox C, et al. 2015. Plastic waste inputs from land into the ocean. Science 347: 768-71.

Jennings S, Mélin F, Blanchard JL, et al. 2008. Global-scale predictions of community and ecosystem properties from simple ecological theory. P Roy Soc Lond B Bio 275: 1375-83.

Kang JH, Kwon OY, Lee KW, et al. 2015. Marine neustonic microplastics around the southeastern coast of Korea. Mar Pollut Bull 96: 304-12.

Kiørboe T. 2011. How zooplankton feed: mechanisms, traits and trade-offs. Biol Rev 86: 311-39.

Koelmans AA, Besseling E, and Shim WJ. 2015. Nanoplastics in the aquatic environment. In: Bergmann M, Gutow L, and Klages M (Eds). Marine anthropogenic litter. Cham, Switzerland: Springer International Publishing AG; doi:10.1007/978-3-319-16510-3_12.

Lattin GL, Moore CJ, Zellers AF, et al. 2004. A comparison of neustonic plastic and zooplankton at different depths near the southern California shore. Mar Pollut Bull 49: 291-94.

Law KL, Moret-Ferguson S, Maximenko NA, et al. 2010. Plastic accumulation in the North Atlantic Subtropical Gyre. Science 329: $1185-88$.

Lebreton LM, Greer S, and Borrero J. 2012. Numerical modelling of floating debris in the world's oceans. Mar Pollut Bull 64: 653-61.

Litchman E, Ohman MD, and Kiørboe T. 2013. Trait-based approaches to zooplankton communities. J Plankton Res 35: 473-84.

Long M, Moriceau B, Gallinari M, et al. 2015. Interactions between microplastics and phytoplankton aggregates: impact on their respective fates. Mar Chem 175: 39-46.

Longhurst AR. 2006. Ecological geography of the sea (2nd edn). San Diego, CA: Academic Press.

Lusher A, McHugh M, and Thompson R. 2012. Occurrence of microplastics in the gastrointestinal tract of pelagic and demersal fish from the English Channel. Mar Pollut Bull 67: 94-99.

Maximenko N, Hafner J, and Niiler P. 2012. Pathways of marine debris derived from trajectories of Lagrangian drifters. Mar Pollut Bull 65: 51-62.

Murray F and Cowie PR. 2011. Plastic contamination in the decapod crustacean Nephrops norvegicus (Linnaeus, 1758). Mar Pollut Bull 62: 1207-17.

Napper IE, Bakir A, Rowland SJ, and Thompson RC. 2015. Characterisation, quantity, and sorptive properties of 
microplastics extracted from cosmetics. Mar Pollut Bull 99: 178-85.

Nelms SE, Duncan EM, Broderick AC, et al. 2015. Plastic and marine turtles: a review and call for research. ICES J Mar Sci 73: 165-81.

Obbard RW, Sadri S, Wong YQ, et al. 2014. Global warming releases microplastic legacy frozen in Arctic Sea ice. Earth's Future 2: 315-20.

PlasticsEurope. 2015. Plastics - the facts 2014/2015. www. plasticseurope.org/Document/plastics-the-facts-20142015. aspx?FolID=2. Viewed 10 May 2016.

Rochman CM. 2015. The complex mixture, fate, and toxicity of chemicals associated with plastic debris in the marine environment. In: Bergmann M, Gutow L, and Klages M (Eds). Marine anthropogenic litter. Cham, Switzerland: Springer International Publishing AG; doi:10.1007/978-3-319-16510-3_5.

Rochman CM, Tahir A, Williams SL, et al. 2015. Anthropogenic debris in seafood: plastic debris and fibers from textiles in fish and bivalves sold for human consumption. Sci Rep 5: 14340.

Setälä O, Fleming-Lehtinen V, and Lehtiniemi M. 2014. Ingestion and transfer of microplastics in the planktonic food web. Environ Pollut 185: 77-83.

Tagg AS, Sapp M, Harrison JP, and Ojeda JJ. 2015. Identification and quantification of microplastics in wastewater using FPA-based reflectance Micro-FT-IR imaging. Anal Chem 87: 6032-40.

Thompson RC, Olsen Y, Mitchell RP, et al. 2004. Lost at sea: where is all the plastic? Science 304: 838.

Turner JT. 2015. Zooplankton fecal pellets, marine snow, phytodetritus, and the ocean's biological pump. Prog Oceanogr 130: 205-48.
UNEP (United Nations Environment Programme). UNEP Frontiers 2016 Report: emerging issues of environmental concern. Nairobi, Kenya: UNEP.

Van Cauwenberghe L and Janssen CR. 2014. Microplastics in bivalves cultured for human consumption. Environ Pollut 193: 65-70.

Van Cauwenberghe L, Vanreusel A, Mees J, and Janssen CR. 2013. Microplastic pollution in deep-sea sediments. Environ Pollut 182: 495-99.

van Sebille E, Wilcox C, Lebreton L, et al. 2015. A global inventory of small floating plastic debris. Environ Res Lett 10: 124006.

van Sebille E, England MH, and Froyland G. 2012. Origin, dynamics, and evolution of ocean garbage patches from observed surface drifters. Environ Res Lett 7: 044040.

Watts AJR, Urbina MA, Corr S, et al. 2015. Ingestion of plastic microfibers by the crab Carcinus maenas and its effect on food consumption and energy balance. Environ Sci Technol 49: 14597-604.

Wilcox C, van Sebille E, and Hardesty BD. 2015. Threat of plastic pollution to seabirds is global, pervasive, and increasing. P Natl Acad Sci USA 112: 11899-904.

Williams RG and Follows MJ. 2003. Physical transport of nutrients and the maintenance of biological production. In: Fasham MJR (Ed). Ocean biogeochemistry. Springer-Verlag Berlin Heidelberg; doi:10.1007/978-3-642-55844-3_3.

Wright SL, Rowe D, Thompson RC, and Galloway TS. 2013. Microplastic ingestion decreases energy reserves in marine worms. Curr Biol 23: 1031-33.

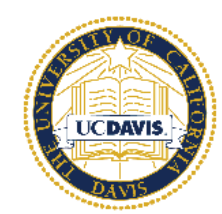

\section{Assistant Professor in Environmental Informatics University of California, Davis}

The Department of Land, Air and Water Resources (LAWR) in the College of Agricultural and Environmental Sciences, University of California, Davis invites applications for a 9-month tenure track faculty position at the assistant level in Environmental Informatics. Research and outreach consistent with the mission of the California Agricultural Experiment Station are also expected. We seek an outstanding scholar to conduct environmental research using geospatial methods and large data sets to study spatial and temporal environmental patterns and processes. A Ph.D. in environmental science, soil science, hydrology, atmospheric science, ecology, geography, informatics, computer science, or a closely related field is required as is a record of research related to environmental processes.

The candidate is expected to maintain an active, externally-funded research program, teach an undergraduate upperlevel core GIS course, an additional upper-level undergraduate GIS or remote sensing course, and a graduate level course in her/his area of expertise (average of 2.5 courses per year), advise undergraduate and graduate students, and participate in professional and university service activities.

For additional information about the position, and to submit application materials, please visit: https://recruit.ucdavis. edu/. Inquiries on topics not addressed by the website can be directed to Dr. Susan L. Ustin, Search Committee Chair, at slustin@ucdavis.edu. The position will remain open until filled but to ensure consideration, applications should be received by August 31, 2016.

UC Davis is an affirmative action/equal employment opportunity employer and is dedicated to recruiting a diverse faculty community. We welcome all qualified applicants to apply, including women, minorities, veterans, and individuals with disabilities. 